\title{
Smaller Regional Gray Matter Volume in Homeless African American Cocaine-Dependent Men: A Preliminary Report
}

\author{
Rosalyn. E. Weller*, ${ }^{*}$, Luke E. Stoeckel ${ }^{1,2}$, Jesse B. Milby ${ }^{1}$, Mark Bolding ${ }^{3}$, Donald B. Twieg ${ }^{4}$, \\ Robert C. Knowlton ${ }^{5}$, Malcolm J. Avison ${ }^{6}$ and Zhaohua Ding ${ }^{6}$
}

${ }^{I}$ Department of Psychology, University of Alabama at Birmingham $(U A B)$, Birmingham, AL, London; ${ }^{2}$ Current address:
Department of Psychiatry, Harvard Medical School and Massachusetts General Hospital, Boston, MA, London;
${ }^{3}$ Department of Vision Sciences, UAB, Birmingham, AL, London; ${ }^{4}$ Department of Biomedical Engineering, UAB,
Birmingham, AL; ${ }^{5}$ Department of Neurology, UAB, Birmingham, AL; ${ }^{6}$ Department of Radiological Sciences and
Vanderbilt University Institute of Imaging Sciences (VUIIS), Nashville, TN, London

Abstract: Models of addiction include abnormalities in parts of the brain involving executive function/inhibitory control. Although previous studies have reported evidence of structural abnormalities in cocaine-dependent individuals, none have specifically targeted the homeless. The present preliminary study investigated brain structure in such an understudied group, homeless, crack-cocaine-dependent African American men $(n=9)$, comparing it to that in healthy controls $(n=8)$. Structural data were analyzed using voxel based morphometry (VBM) and a regions of interest (ROI) analysis. Homeless cocaine-dependent individuals had smaller gray matter volume in dorsolateral prefrontal cortex, anterior cingulate, the cerebellum, insula, and superior temporal gyrus. Most of these areas subserve executive function or inhibitory control. These results are similar to those found in most previous studies of non-homeless cocaine-dependent individuals. Reduced gray matter in executive function/inhibitory control regions of the brain in cocaine-dependent individuals may be a preexisting risk factor for the development of addiction and/or a consequence of drug abuse.

Keywords: Addiction; VBM; executive function; inhibitory control.

\section{INTRODUCTION}

Models of addiction have suggested that drug-seeking behavior is related to abnormal activity in multiple neural circuits. One is the executive function, inhibitory control circuit [1-4]. In people with an addiction, the heightened motivational value of drugs and associated cues, coupled with deficient executive function mechanisms, including inhibitory control, can result in relatively greater drugseeking and drug-using behavior [5]. Anatomical studies of the brains of cocaine-dependent individuals have found less gray matter volume in areas including dorsolateral prefrontal cortex, anterior cingulate cortex, lateral and medial orbitofrontal cortex, cerebellum, amygdala, insula, and superior temporal cortex [e.g., 6-11; but see 12]. Abnormalities in some of these regions (e.g., dorsolateral prefrontal cortex, anterior cingulate, cerebellum) may contribute to the executive function and inhibitory control deficits reported in cocaine abusers [13-17].

In the present exploratory study, we used voxel-based morphometry (VBM) [18, 19], a quantitative approach to magnetic resonance image (MRI) analysis that is automated and nonbiased, in homeless crack-cocaine-dependent men. Although previous anatomical studies of cocaine-dependent

\footnotetext{
*Address correspondence to this author at the UAB Department of Psychology, 415 Campbell Hall, University of Alabama at Birmingham, Birmingham, AL 35294-1170, UK; Tel: 205-934-8563; Fax: 205-975-6110; E-mail reweller@uab.edu
}

individuals have used VBM $[6,8,10-12,20]$, two of the six studies reported gray matter density but not volume changes $[6,8]$. Additionally, only two of the six studies used a 3 Tesla rather than 1.5 Tesla magnet $[11,12]$, with the former's higher gray matter to white matter contrast/noise ratio [21] that would be expected to lead to better segmentation in VBM. Most significantly, our preliminary study is the first to investigate brain structure in explicitly homeless cocaine-dependent individuals. These individuals represent a unique but understudied subgroup of cocaine abusers, a subgroup that can be seen as representing one of the more extreme and devastating outcomes along the trajectory of addiction. We hypothesized that homeless cocaine-dependent individuals, compared to healthy controls, would have less gray matter volume in areas reported as abnormal in non-homeless cocaine-dependent individuals. In particular, we hypothesized that regions such as dorsolateral prefrontal cortex, anterior cingulate cortex, and the insula, related to executive function, inhibitory control, and autonomic reactivity to emotional stimuli [e.g., $9,22,23$; for review see 24], would show less gray matter volume.

\section{METHODS}

\section{Participants}

\section{Cocaine Group}

The cocaine-dependent men $(\mathrm{n}=9)$ were recruited from Birmingham Healthcare (BHC), the largest agency serving 
homeless persons in Alabama. They were newly enrolled participants in a cognitive-behavioral treatment program for chronic crack cocaine-dependent individuals [25]. Eligibility criteria for the treatment program were: 1) McKinney Act homelessness [26];2) cocaine dependence according to DSM-IV [27], with self-reported cocaine use within the last two weeks; and 3) significant psychological distress, as signaled by a score of 70 on one or more Brief Symptom Inventory (BSI) Scales [28]. Other DSM-IV Axis I nonpsychotic diagnoses were present and in order of most prevalent were: Anxiety Mediated Disorders (especially Simple Phobia and Generalized Anxiety Disorder) and Depression Disorders (Major Depressive Disorder, Dysthymia, and Depressive Disorder not otherwise specified). To obtain a sample that was representative of the homeless cocaine-dependent population, we used a list of exclusionary criteria for the MRI study that controlled for the most obvious alternative factors that could influence our results while still maintaining a representative sample. Exclusionary criteria consisted of: 1) not being right-handed, as assessed with a score of at least 8 of 10 right-handed responses to the Edinburgh Handedness Inventory [29]; 2) showing signs of or having a history of a neurological disease or other brain abnormality; 3) being HIV positive; and 4) having worse than 20/60 vision reading a Snellen eye chart without corrective glasses. Use of alcohol was permitted as long as cocaine was the primary substance abused. All participants were within the first three weeks of treatment and were abstinent for 1-19 days (mean $=4.8$ days, $\mathrm{SD}=7.1$ ) before imaging.

\section{Control Group}

Non-cocaine-dependent men $(\mathrm{n}=9)$ were recruited from the Birmingham area. Control subjects were allowed use of alcohol but no current or prior history of a DSM-IV alcohol or substance abuse disorder, or use of illegal drugs. They were matched with the cocaine subjects on ethnicity, age, and handedness. We subsequently excluded MRI data from one control participant when we learned that he had inaccurately described his years of education completed, reporting 12 rather than the actual 16 years. This left us with a final control $\mathrm{n}$ of 8 . We initially attempted to recruit homeless men who had never used drugs as controls, but were unsuccessful. Studies have suggested that most (78.3\%) homeless adults in urban areas meet criteria for or have a history of substance abuse/dependence [30], which could explain why we had difficulty finding eligible homeless control participants.

Prior to imaging, participants completed the Center for Epidemiological Studies Depression Scale (CES-D) [31]. The CES-D is not a diagnostic tool for depression per se, but focuses on how social stressors impinge on persons who are disadvantaged and is used as a community screening device to refer people to care [32]. Approximately $8 \%$ of individuals in the general population score above 16 on the CES-D, indicating significant symptoms of depression, whereas approximately $78 \%$ of homeless persons score above 16.

All participants were African American males of ages $33-50$ (cocaine abusers, mean $=41.0$ years, $\mathrm{SD}=5.7$; controls, mean $=39.5$ years, $\mathrm{SD}=5.4$ ). Independent-samples $t$ tests were used to compare the means of the two groups on the variables of age, maximum years of education completed, and CES-D scores. There were no significant group differences on age. However, the cocaine group was less educated (11.56 years \pm 0.18 vs. 13.25 years \pm 0.37 for controls) and had higher scores on the CES-D scale (23.00 \pm 4.56 vs. $4.63 \pm 1.03$ for controls; $p<0.01$ ).

\section{Participant Procedures}

All procedures involving the use of research participants followed NIH guidelines and were reviewed and approved by UAB's Institutional Review Board for Human Use.

The afternoon imaging session took about an hour. It also included an fMRI study, the results of which are not reported. Cocaine-dependent participants were debriefed after the imaging session to ensure that possible cocaine craving induced by the drug-related cues presented during the fMRI scan did not result in increased drug use and were paid \$25 for their participation.

\section{VBM Study}

\section{MRI Data Acquisition}

The neuroimaging studies were conducted using a Philips Intera ultra-short bore $(1.57 \mathrm{~m}), 3.0$ Tesla $(\mathrm{T})$ magnet with parallel imaging capabilities (SENSE). For the high resolution anatomical scan used for the VBM analysis, 160, $1 \mathrm{~mm}$ thick parasagittal 3-D slices were acquired using a T1 Turbo-field Echo (TFE) sequence with a SENSE factor of 2 in S (R-L), inversion time of $400 \mathrm{~ms}$, a TR of $9.9 \mathrm{~ms}$, TE of $4.6 \mathrm{~ms}, 8^{\circ}$ flip angle, and a scan resolution of $240 \times 200$, reconstructed to $256 \times 256$ for a FOV of $240 \times 240 \times 160$ $\mathrm{mm}$. The measured voxel size was $1.2 / 1 / 1 \quad(\mathrm{M} / \mathrm{P} / \mathrm{S})$, reconstructed to near isotropic resolution of 1/.9/.9.

\section{VBM Data Analysis}

The images were motion-corrected and then analyzed using the optimized VBM procedures of Good et al. [19], a modification of the protocol of Ashburner and Friston [18]. This included creation of a customized, study-specific brain template, use of a standard $12 \mathrm{~mm}$ Gaussian filter for smoothing, and modulation of the segmented and normalized images to correct volume changes by the Jacobian determinant of the transformation matrices. VBM was used to compute total gray matter, white matter, and CSF volume so that group comparisons could be made. Images were analyzed using statistical parametric mapping as implemented in the SPM2 software package (Statistical Parametric Mapping, Wellcome Department of Cognitive Neurology, London, UK). Statistical parametric maps were generated within the context of the General Linear Model, and group differences in regional gray matter volume were assessed using independent samples t-tests $(p<.001$, uncorrected, $\geq 7$ contiguous voxels). Selection of nine gray matter ROIs was mainly based on regions related to executive function, inhibitory control, and reactivity to emotional stimuli as it may impact decision-making, reported as abnormal in previous MRI papers on cocainedependent individuals $[6,8,10,11,33]$. These ROIs were: dorsolateral prefrontal cortex (separately for the middle frontal gyrus, MFG, and inferior frontal gyrus, IFG), anterior cingulate cortex, lateral orbitofrontal cortex, medial orbitofrontal cortex, insula, superior temporal gyrus, 
amygdala, and cerebellum. Left and right sides were considered separately. The ROIs were defined according to the templates within the WFU PickAtlas [34, 35], which included the AAL Library templates [36]. We computed the percent difference in the largest cluster of contiguous voxels showing a statistically significant group difference in gray matter volume within each ROI. We also computed the percent difference between groups in total volume for a given ROI (see Table 1).

\section{RESULTS}

There were no significant overall group differences across the entire brain in total gray matter, white matter, or cerebrospinal fluid volume $(\mathrm{p}<.05)$.

Of the nine ROIs, five showed significantly less gray matter volume in the cocaine-dependent men compared to the controls (Fig. 1; Table 1). These were right dorsolateral prefrontal cortex (IFG), right anterior cingulate, right and left posterior insula, right superior temporal gyrus, and right and left cerebellum (Fig. 2). Although the group differences in each cluster were substantial, ranging from about a mean of $18 \%-46 \%$, given the small sizes of most of the clusters relative to the total sizes of the ROIs, the percent difference in gray matter volume in each ROI was smaller, ranging from .1\% (left cerebellum) to $17.5 \%$ (right insula; Table 1). Because there was a significant group difference in maximum education level achieved, we also analyzed the VBM gray matter volume data while statistically controlling for education (ANCOVA, $\mathrm{p}<.001$, uncorrected, cluster extent $\geq 7$ contiguous voxels). The ANCOVA revealed a similar pattern of results to that found leaving education out of the analysis; i.e., less gray matter volume in the cocainedependent men in right dorsolateral prefrontal cortex (IFG), right anterior cingulate, right cerebellum, bilateral superior temporal gyrus, and bilateral insula.

\section{DISCUSSION}

In this preliminary study, we found less gray matter in the cocaine-dependent men in areas subserving executive function, inhibitory control, and reactivity to emotional stimuli as it may affect decision making. These areas were right dorsolateral prefrontal cortex, right anterior cingulate cortex, right and left insula, right superior temporal gyrus, and the left cerebellum.

\section{VBM Results, Overall Brain Volume}

We found no significant group differences between the cocaine-dependent men and the control participants in total gray matter, white matter, or CSF volume. These results agree with those of most previous studies that reported that global brain atrophy does not follow cocaine addiction [37-39; but see 40, 41].

\section{VBM Results, Regional Gray Matter Volume}

Most previous studies comparing the brain anatomy of cocaine-dependent individuals to non-cocaine-using controls have reported decreased volume or density of regions such as dorsolateral prefrontal cortex, anterior cingulate cortex, insula, superior temporal cortex, cerebellum, orbitofrontal cortex, and the amygdala, involved in executive function, inhibitory control, autonomic reactivity as it may impact decision-making, and the reward system $[6,8,10,11,42$,
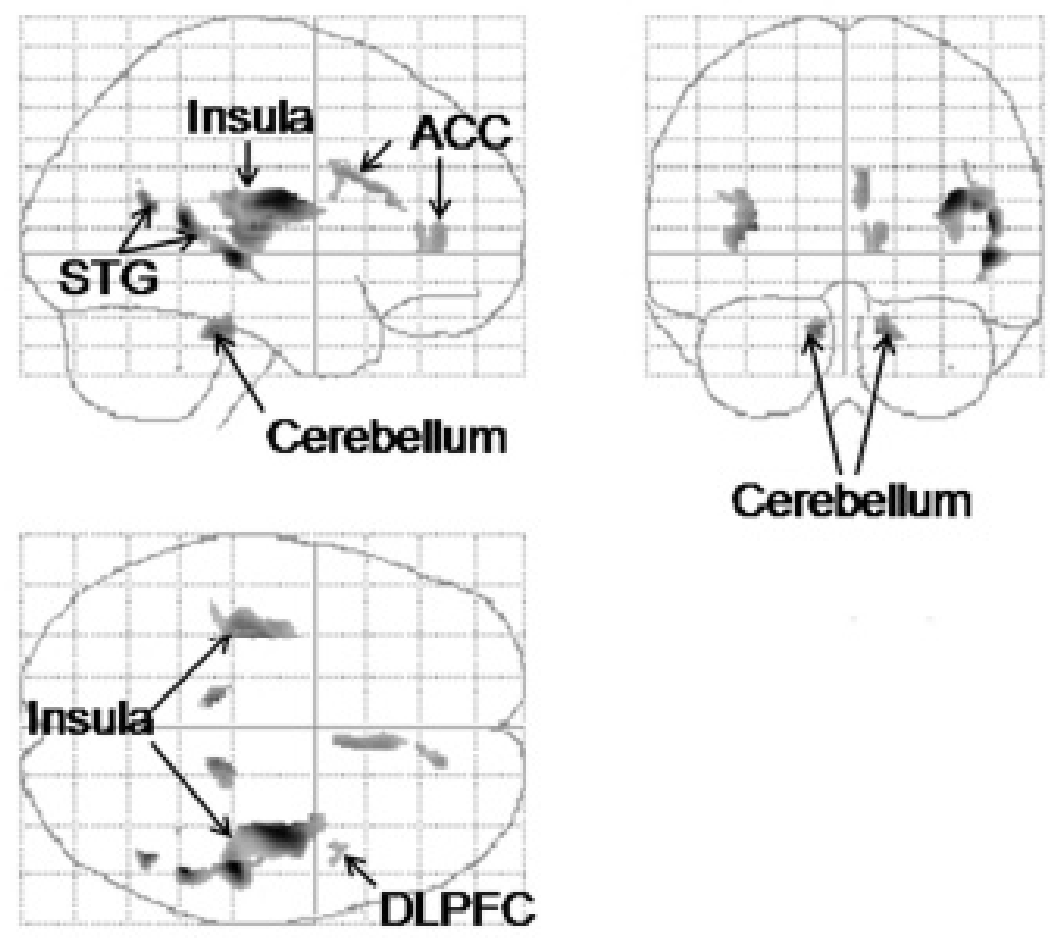

Fig. (1). A statistical parametric map in "glass brain" format of regions identified by VBM and a ROI analysis with significantly smaller gray matter volumes in the cocaine-dependent subjects. Upper left, lateral or sagittal view; upper right, anterior or coronal view; and lower left, dorsal or axial view. ACC, anterior cingulate cortex; DLPFC, dorsolateral prefrontal cortex; STG, superior temporal gyrus. $\mathrm{p}<.001$, uncorrected, cluster size $\geq 7$ contiguous voxels. 
Table 1. Gray Matter Volume Reductions in the Cocaine-Dependent vs. Non-Cocaine-Dependent Men, as Determined from an ROI Analysis ${ }^{1}$

\begin{tabular}{|c|c|c|c|c|c|c|c|c|}
\hline ROI & Side & Cluster & $\mathbf{x}$ & $\mathbf{y}$ & $\mathbf{z}$ & $\mathbf{t}$ & \% CI & ROI \\
\hline \hline DLPFC (IFG) & $\mathrm{R}$ & 86 & 41 & 5 & 31 & 4.35 & 36.4 & .5 \\
\hline ACC & $\mathrm{R}$ & 348 & 7 & 13 & 27 & 5.09 & 42.5 & 4.4 \\
\hline Insula & $\mathrm{R}$ & 274 & 12 & 43 & 7 & 4.71 & 45.1 & 3.4 \\
\hline & $\mathrm{R}$ & 2488 & 37 & -12 & 19 & 7.52 & 36.4 & 17.5 \\
\hline STG & $\mathrm{L}$ & 1303 & -31 & -15 & 13 & 6.10 & 39.9 & 9.1 \\
\hline Cerebellum & $\mathrm{R}$ & 846 & 49 & -27 & -1 & 7.85 & 45.8 & 2.6 \\
\hline & $\mathrm{L}$ & 155 & -35 & -26 & 7 & 5.41 & 39.9 & .5 \\
\hline
\end{tabular}

${ }^{1}$ IFG, inferior frontal gyrus; L, left, R, right; other abbreviations as in text. $\mathrm{x}, \mathrm{y}, \mathrm{z}, \mathrm{MNI}$ coordinates with $\mathrm{x}$ lateral and left negative, $\mathrm{y}$ anteroposterior with posterior negative, and $\mathrm{z}$ dorsoventral with ventral negative, the latter two relative to the anterior commissure. Only the largest cluster for an $\mathrm{ROI}$ is shown. \% $\mathrm{Cl}$, \% decrease in volume for cocaine subjects compared to controls within the largest cluster, \% ROI, \# voxels with decreased volume for cocaine subjects vs. controls / total \# voxels in the ROI mask. p <.001, uncorrected; cluster extent $\geq 7$.

${ }^{2}$ The cluster in the left superior temporal gyrus is a continuation of the one in the insula.

43]. Those with cocaine-dependence were also found to have reduced cortical thickness in regions involved in executive regulation, the right dorsolateral prefrontal cortex and insula [40]. Years of cocaine use in cocaine-dependent individuals were found to be negatively correlated with the volume of regions that included the middle frontal gyrus, insula, and cerebellum [20]. We found gray matter volume reductions in most of these regions, in particular the dorsolateral prefrontal cortex (the IFG), anterior cingulate, insula, superior temporal cortex, and cerebellum. The reduced volumes were mainly right-lateralized.

Our review of the literature suggests that we are the first to find reduced gray matter volume in the anterior cingulate, insula, and dorsolateral prefrontal cortex (middle and inferior frontal gyri) of cocaine-dependent subjects, although these areas were previously found to have reduced gray matter density [6, 8] or, for dorsolateral prefrontal and insular cortex, to be thinner [40]. Finding abnormalities in the insula is not surprising, given that the middle cerebral artery, which provides the blood supply to the insular and superior temporal region [44], is a commonly reported site of cocaine-induced vascular accidents or cerebral infarcts due to cocaine use $[45,46]$.

We did not find less gray matter volume for the amygdala, in agreement with results of previous studies of Jacobsen et al. [39] and Sim et al. [10], but in contrast to results of Makris and collaborators [40]. Differences in methodological details between the studies may account for these differences.

\section{Significance of VBM Findings}

Cocaine abusers or polysubstance abusers who mainly abuse cocaine show deficits on tests of executive function [e.g., 15, 16]. Executive function is attributed in general to prefrontal cortex as well as to other regions such as the anterior cingulate and cerebellum [9, 23, 24, 47]. All three of these regions showed smaller regional gray matter volume in our study of cocaine-dependent individuals. The region of reduced gray matter volume found in the inferior frontal gyrus of dorsolateral prefrontal cortex, albeit small, may be functionally important because of the involvement of this area in decision-making, executive function, and inhibitory control [e.g., 13, 48-50; for review see 24]. Volkow and colleagues [51] found that when cocaine-dependent individuals were asked to cognitively inhibit their drug craving while watching a cocaine-related video, decreases in metabolic activity in limbic regions such as the nucleus accumbens and orbitofrontal cortex were associated with increases in the right inferior frontal gyrus, presumably because of the latter's role in inhibitory control. Cocainedependent individuals performing tasks of inhibitory control (the Go/No-go and Stroop tasks) and decision-making (the Iowa Gambling Task) showed reduced activity in prefrontal as well as anterior cingulate cortex [52-56].

Decision making as it relates to impulsivity, as shown by more immediate choices on a delay discounting of money task, was found to be negatively correlated with gray matter volume in dorsolateral and inferolateral frontal cortex in normal, non-drug-dependent men [57]. This suggests that reduced gray matter volume in cocaine-dependent individuals could be a risk factor for the development of addiction, although the additional effects of cocaine use cannot be ruled out.

Sim and colleagues also reported reduced gray matter volume in the cerebellum of cocaine-dependent individuals [10], as we found in the present study. In addition to its motor roles, the cerebellum also plays a role in executive function $[9,23]$. As noted by Sims et al. [10], cocaine useinduced cerebral vasoconstriction may have promoted cell damage in the cerebellum, although reduced cerebellar gray matter volume could also have been a pre-existing condition.

The greatest difference in gray matter volume in cocainedependent participants compared to controls in the present study was in the insula. Although no previous structural studies of cocaine subjects reported smaller gray matter volume in the insula, reduced insular gray matter density, cortical thinning, and reduced white matter volume have been found $[6,40,45,58]$. The insula, a large region that has 

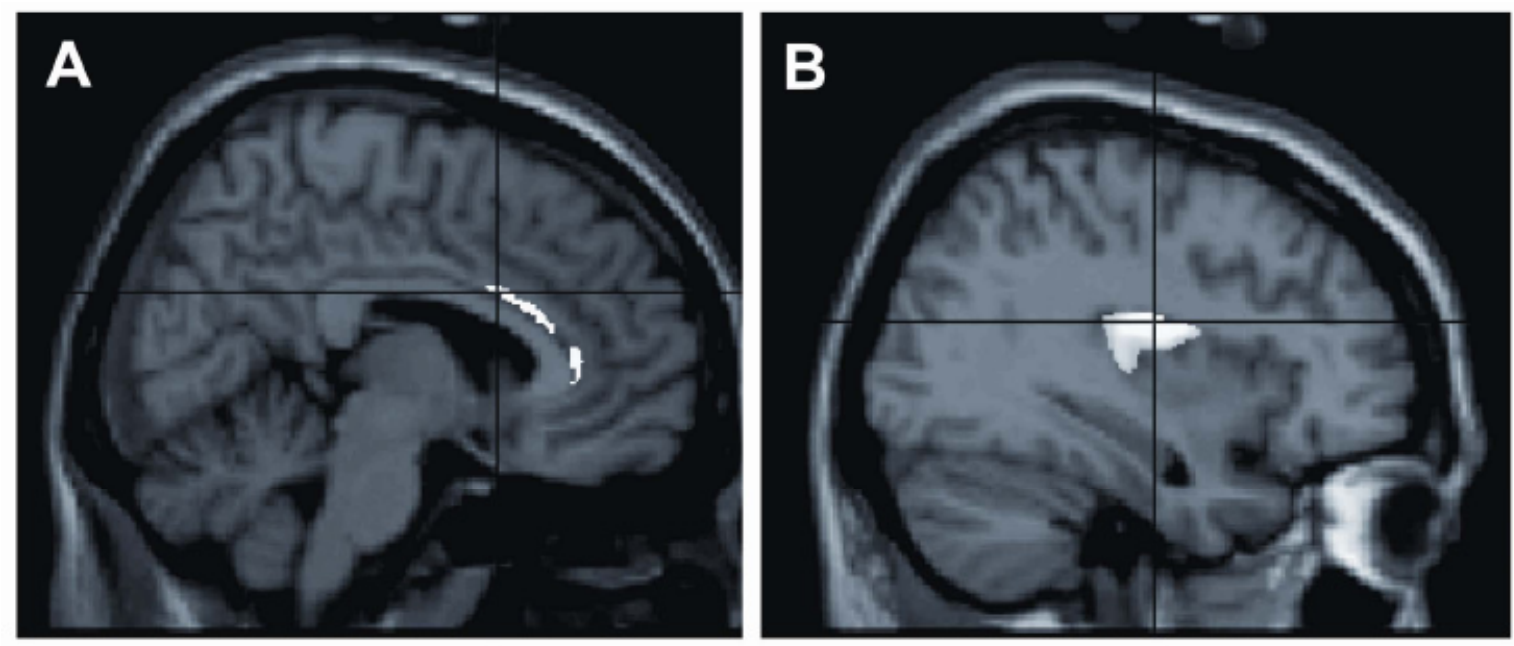

Fig. (2). Some areas found in the ROI analysis to have reduced gray matter volume in the cocaine-dependent men, overlaid on the SPM2 single-subject T1 template. A, sagittal view to show reduced gray matter volume in the right anterior cingulate cortex. B, sagittal view to show reduced gray matter volume in the right insula. Reductions in other areas are not shown (are masked). p $<.001$, uncorrected, cluster size $\geq 7$ voxels

been implicated in a variety of roles including somatosensory integration, pain perception, craving, self awareness, and decision-making, is also involved in interoception, the sense of the internal physiological state of the body [22, 59-63]. According to the somatic marker hypothesis, deficits in emotional signaling or interoception can result in poor decision-making [64]. A deficit in autonomic reactivity may mean that the reward circuit is overwhelmed by the incentive salience of drug stimuli without being adequately modulated by emotional signals related to drugs or drug cues.

Finally, we, like others, also found reduced gray matter volume or density in cocaine-dependent individuals in the superior temporal gyrus $[6,10]$. This result is perhaps not surprising, given the proximity of superior temporal cortex to the insula, their interconnections [65; for review see 62], and the significant volume reduction we found in the insula. Additionally, superior temporal cortex and the insula share some overlap in function [63] related, in particular, to emotion [60].

Previous neural models of addiction have emphasized how cognitive dysfunctions could impact drug dependence [for review see 1,3]. For example, the I-RISA - impaired response inhibition and salience attribution - model of Goldstein and Volkow [66] emphasized how cognitive dysfunctions could contribute to, or exacerbate drug dependence, perhaps by predisposing someone to first try drugs [5]. We are similarly suggesting that the smaller brain volumes in the cocaine-dependent individuals in areas that other studies have suggested play a role in executive function and inhibitory control may render them particularly vulnerable to reward system activation by salient cocaine cues. This connection should be considered speculative given that our study did not report convergent results for our participants on tests of inhibitory control or executive function. Structural deficiencies in homeless crack-cocainedependent individuals in areas that are involved in executive function may be viewed as a risk factor that contributed to the development of addiction, the result of the use of crack cocaine, or both [e.g., 40]. Some of the regions showing smaller brain volumes, such as the insula, are in areas that are susceptible to damage induced by cocaine use and could be the result of cocaine use. This may mean that smaller regional size may not have been an initial factor leading to drug abuse, but once present as a result of drug use, perhaps contributed to an increased propensity to continue drug use. Other regions of smaller volume were in areas that subserve cognitive functions found to be deficient in cocaine abusers. Whether these volume differences were the result of drug use or pre-existing risk factors for developing an addiction is uncertain.

\section{Limitations of Study}

The results of this study should be considered in light of the uniquely homogeneous sample of cocaine-dependent subjects and relatively small samples sizes used. The cocaine abusers were all homeless African American men. Homeless individuals have undoubtedly been understudied in the past, given the inherent complications in contacting and scheduling a neuroimaging session for such a group, as well as their unfamiliarity and possible reticence about medical procedures such as MR scans. The reality of addiction is that many chronic crack cocaine users are likely to have no permanent housing [67]. The fact that the results we found were quite similar to those previously observed for other (non-homeless) samples is especially interesting. Although all the cocaine-dependent participants were homeless, and homelessness or nutritional status could affect brain morphology and function, we failed to find any significant overall group differences across the entire brain in total gray matter, white matter, or cerebrospinal fluid volume $(p<.05)$. Although our control participants were not matched on homelessness, we think it unlikely that homeless status was a confounding factor in our study, as our VBM results agree in general with those of previous studies of cocaine-dependent individuals. Although homeless cocaine-dependent individuals are a difficult population to study, especially in the context of neuroimaging research, and have possible confounding co-morbidities, it is important that findings 
from this population be obtained as they represent the reality of drug addiction for a very important subgroup of the population.

Given the limited sample sizes, we chose to study men to minimize variability due to gender differences which have been reported in the literature [e.g., 68, 69] in order to increase power to detect effects more specifically related to our hypotheses.

Our cocaine-dependent participants also scored higher on a depression scale than controls and some had a DSM-IV axis I disorder related to depression. This result is not surprising, given that previous studies have reported a high prevalence of depression in cocaine abusers [70], with one study of crack-cocaine smokers finding $80 \%$ with symptoms of more than minimal drepression and $55 \%$ with symptoms of moderate to severe depression [71]. Those with unipolar depression have less brain tissue in some of the same regions that were smaller in our sample of cocaine-dependent participants [72-74; for review see 75, 76]. Cocainedependent participants were also not excluded for use of alcohol, and alcohol addiction has been found correlated with lower gray matter volumes in some of the same regions that we found to be smaller in our study [e.g., 77]. However, alcoholics also show less overall brain gray matter [77], which we did not find. In addition, previous studies reported that men dependent on both crack cocaine and alcohol showed no additional structural changes compared to men dependent on crack cocaine alone [42, 43, 78]. Finally, it should be noted that some of our cocaine-dependent participants also had a DSM-IV axis I anxiety disorder.

\section{CONCLUSION}

Models of addiction include abnormalities in parts of the brain involving executive function/inhibitory control. Although previous studies have reported evidence of structural abnormalities in cocaine-dependent individuals, none have specifically targeted the homeless. The present preliminary study investigated brain structure in such an understudied group, homeless, crack-cocaine-dependent African American men, comparing it to that in healthy controls. Structural (MRI) data were analyzed using voxel based morphometry (VBM) and a regions of interest (ROI) analysis. Homeless cocaine-dependent individuals had smaller gray matter volume in dorsolateral prefrontal cortex, anterior cingulate, the cerebellum, insula, and superior temporal gyrus, areas mainly functioning in executive function or inhibitory control. These results are similar to those found in non-homeless cocaine-dependent individuals.

\section{ACKHOWLEDGEMENTS}

Beverly A. Bush, Ph.D., contributed to subject testing. Michele Freedman, Ph.D., Michele Gould, M.S., and L. A. Bell helped with subject recruitment. This research was funded by NIDA 3R01 DA11789 (Milby). Resources were provided by UAB's Center for Nuclear Imaging Research (CNIR) and Center for the Development of Functional Neuroimaging (CDFI), and Vanderbilt University's Institute of Imaging Science (VUIIS). Some of these results were presented previously at scientific meetings $[79,80]$.

\section{REFERENCES}

[1] Baler RD, Volkow ND. Drug addiction: the neurobiology of disrupted self-control. Trends Molecular Med 2006; 12: 559-66.

[2] Jentsch JD, Taylor JR. Impulsivity resulting from frontostriatal dysfunction in drug abuse: implications for the control of behavior by reward-related stimuli. Psychopharm 1999; 146: 373-90.

[3] Koop GF, Volkow ND. Neurocircuitry of addiction. Neuropsychopharm 2010; 35: 217-38.

[4] Volkow ND, Fowler JS. Addiction, a disease of compulsion and drive: involvement of the orbitofrontal cortex. Cerebral Cortex 2000; $10: 318-25$.

[5] Garavan H, Hester R. The role of cognitive control in cocaine dependence. Neuropsychol Rev 2007; 17: 337-45.

[6] Franklin TR, Acton PD, Maldjian JA, et al. Decreased gray matter concentration in the insular, orbitofrontal, cingulate, and temporal cortices of cocaine patients. Biol Psychiatry 2002; 51: 134-42.

[7] Makris N, Gasic GP, Seidman LJ, et al. Decreased absolute amygdala volume in cocaine addicts. Neuron 2004; 44: 729-40.

[8] Matochik JA, London ED, Eldreth DA, Cadet J-L, Bolla KI. Frontal cortex tissue composition in abstinent cocaine abusers: a magnetic resonance imaging study. Neuroimage 2003; 19: 10951102 .

[9] Schmahmann JD, Sherman JC. The cerebellar cognitive affective syndrome. Brain 1998; 121: 561-79.

[10] Sim ME, Lyoo IK, Streeter CC, et al. Cerebellar gray matter volume correlates with duration of cocaine use in cocainedependent subjects. Neuropsychopharm 2007; 32: 2229-37.

[11] Tanabe J, Tregellas JR, Dalwani M, Thompson L, Owens E, Crowley T, Banish M. Medial orbitofrontal cortex gray matter is reduced in abstinent substance-dependent individuals. Biol Psychiatry 2009; 65: 160-4.

[12] Narayana PA, Datta S, Tao G, Steinberg JL, Moeller FG. Effect of cocaine on structural changes in brain: MRI volumetry using tensor-based morphometry. Drug Alcohol Depend 2010; 111: 1919.

[13] Chambers CD, Bellgrove MA, Stokes MG, et al. Executive "brake failure" following deactivation of human frontal lobe. J Cog Neurosci 2006; 18: 444-55.

[14] Fillmore MT, Rush CR. Impaired inhibitory control of behavior in chronic cocaine users. Drug Alcohol Depend 2002; 66: 265-73.

[15] Goldstein RZ, Leskovjan AC, Hoff AL, et al. Severity of neuropsychological impairment in cocaine and alcohol addiction: association with metabolism in the prefrontal cortex. Neuropsychologia 2004; 42: 1447-58.

[16] Verdejo-García A, Pérez-García M. Profile of executive deficits in cocaine and heroin polysubstance users: common and differential effects on separate executive components. Psychopharm (Berlin) 2007; 190: 517-30.

[17] Verdejo-García A, Pérez-García M, Bechara A. Emotion, decisionmaking and substance dependence: a somatic marker model of addiction. Curr Neuropharm 2006; 4: 17-31.

[18] Ashburner J, Friston K. Voxel-based morphometry - The methods. NeuroImage 2000; 11: 805-21.

[19] Good CD, Johnsrude IS, Ashburner J, Henson RN, Friston KJ, Frackowiak RS. A voxel-based morphometric study of ageing in 465 normal adult human brains. NeuroImage 2001; 14: 21-36.

[20] Barrós-Loscertales A, Garavan H, Bustamante JC, et al. Reduced striatal volume in cocaine-dependent patients. NeuroImage 2011; doi: 10.1016/j.neuroimage.2011.02.035.

[21] Lu H, Nagae-Poetscher LM, Golay X, Lin D, Pomper M, van Zij1 CM. Routine clinical brain MRI sequences for use at 3.0 Tesla. J Mag Res Imaging 2005; 22: 13-22.

[22] Craig AD. How do you feel? Interoception: the sense of the physiological condition of the body. Nat Rev Neurosci 2002; 3: 655-66.

[23] Gottwald B, Wilde B, Mihajlovic Z, Mehdorn HM. Evidence for distinct cognitive deficits after focal cerebellar lesions. J Neurol Neurosurg Psychiatry 2004; 75: 1524-31.

[24] Aron JL, Paulas MP. Location, location: using functional magnetic resonance imaging to pinpoint brain differences relevant to stimulus use. Addiction 2007; 103 (Suppl. 1): 33-43.

[25] Milby JB, Schumacher JE, Vuchnich R, Freedman MJ, Kertesz S, Wallace D. Towards cost effective initial care for substance abusing homeless. J Substance Abuse Treatment 2008; 34: 180-91.

[26] Stewart B. McKinney Homelessness Assistance Act. Public Law 100-177, 1987. 
[27] Diagnostic and Statistical Manual of Mental Disorders, Fourth Edition, Revised. Washington, D.C.: American Psychiatric Association 1994

[28] Derogatis LR. SC-90: Administration, Scoring and Procedures Manual. Baltimore, MD: Clinical Psychometric Research 1977.

[29] Oldfield RC. The assessment and analysis of handedness: the Edinburgh inventory. Neuropsychologia 191; 9: 97-113.

[30] O'Toole TP, Conde-Martel A, Gibbon JL, Hanusa BH, Freyder PJ, Fine MJ. Substance-abusing urban homeless in the late 1990s: how do they differ from non-substance-abusing homeless persons? J Urban Health 2004; 81: 606-17.

[31] Radloff LS. The CES-D Scale: A self-report depression scale for research in the general population. Applied Psychol Measurement 1977; 1:385-401.

[32] Ritchey FJ, LaGory M, Fitzpatrick K, Mullis J. A comparison of homeless, community-wide and selected distressed samples on the CES-Depression Scale. Amer J Public Health 1990; 80: 1384-6.

[33] Anderson CM, Maas LC, Frederick B deB, et al. Cerebellar vermis involvement in cocaine-related behaviors. Neuropsychopharm 2006; 31: 1318-26.

[34] Maldjian JA, Laurienti PJ, Kraft RA, Burdette JB. An automated method for neuroanatomic and cytoarchitectonic atlas-based interrogation of fMRI data sets. NeuroImage 2003; 19: 1233-9.

[35] Maldjian JA, Laurienti PJ, Burdette JH. Precentral gyrus discrepancy in electronic versions of the Talairach atlas. NeuroImage 2004; 21: 450-55.

[36] Tzourio-Mazoyer N, Landeau B, Papathanassious D, et al. Automated anatomical labeling of activations in SPM using a macroscopic anatomical parcellation of the MNI MRI singlesubject brain. NeuroImage 2002; 15: 273-89.

[37] Bartzokis G, Beckson M, Lu PH, et al. Increased CSF volumes are associated with diminished subjective responses to cocaine infusion. Neuropsychopharm 2000; 23: 468-73.

[38] Di Sclafani V, Clark HW, Tolou-Shams M, et al. Premorbid brain size is a determinant of functional reserve in abstinent crackcocaine and crack-cocaine-alcohol-dependent adults. J Internat Neuropsychol Soc 1998; 4: 559-65.

[39] Jacobsen LK, Giedd JN, Kreek MJ, Gottschalk C, Kosten TR. Quantitative medial temporal lobe brain morphology and hypothalamic-pituitary-adrenal axis function in cocaine dependence: a preliminary report. Drug Alcohol Depend 2001; 62: 49-56.

[40] Makris N, Gasic GP, Kennedy DN, et al. Cortical thickness abnormalities in cocaine addiction - a reflection of both drug use and a pre-existing disposition to drug abuse? Neuron 2008; 60: 174-88.

[41] Pascual-Leone A, Dhuna A, Anderson DC. Cerebral atrophy in habitual cocaine abusers. Neurology 1991; 41: 34-7.

[42] Fein G, Di Sciafani V, Meyerhoff DJ. Prefrontal cortex volume reduction associated with frontal cortex functional deficit in 6-week abstinent crack-cocaine dependent men. Drug Alcohol Depend 2002; 68: 87-93.

[43] O'Neill J, Cardenas VA, Meyerhoff DJ. Separate and interactive effects of cocaine and alcohol dependence on brain structures and metabolites: quantitative MRI and proton MR spectroscopic imaging. Addiction Biol 2001; 6: 347-61.

[44] Stoeckel MC, Wittsack H-J, Meisel S, Seitz R. Pattern of cortex and white matter involvement in severe middle cerebral artery ischemia. J Neuroimaging 2007; 17: 131-40.

[45] Bartzokis G, Beckson M, Hance DB, et al. Magnetic resonance imaging evidence of 'silent' cerebrovascular toxicity in cocaine dependence. Biol Psych 1999; 45: 1203-11.

[46] Johnson BA, Dawes MA, Roache JD, et al. Acute intravenous lowand high-dose cocaine reduces quantitative global and regional cerebral blood flow in recently abstinent subjects with cocaine use disorder. J Cerebral Blood Flow Metab 2005; 25: 928-36.

[47] Fuster JM. Executive frontal functions. Exper Brain Res 2002; 133: 66-70.

[48] Aron AR, Fletcher PC, Bullmore ET, Sahakian BJ, Robbins TW. Stop-signal inhibition disrupted by damage to right inferior frontal gyrus in humans. Nat Neurosci 2003; 6: 115-16.

[49] Fecteau S, Pascual-Leone A, Zald DH, et al. Activation of prefrontal cortex by transcranial direct current stimulation reduces appetite for risk during ambiguous decision making. J Neurosci 2007; 27: 6212-8.
[50] Garavan H, Hester R, Murphy K, Fassbender C, Kelly C. Individual differences in the functional neuroanatomy of inhibitory control. Brain Res 2006; 1105: 130-42.

[51] Volkow ND, Fowler JS, Wang G-J, et al. Cognitive control of drug craving inhibits brain reward regions in cocaine abusers. NeuroImage 2010; 49: 2536-43.

[52] Bolla KI, Eldreth DA, London ED, et al. Orbitofrontal cortex dysfunction in abstinent cocaine abusers peforming a decisionmaking task. NeuroImage 2003; 19: 1085-94.

[53] Bolla K, Ernst M, Kiehl K, et al. Prefrontal cortical dysfunction in abstinent cocaine abusers. J Neuopsychiatry Clin Neurosci 2004; 16: 456-65.

[54] Hester R, Garavan H. Executive dysfunction in cocaine addiction: Evidence for discordant frontal, cingulate, and cerebellar activity. $\mathrm{J}$ Neurosci 2004; 24: 11017-22.

[55] Kaufmann JN, Ross TJ, Stein EA, Garavan H. Cingulate hypoactivity in cocaine users during a GO-NOGO task as revealed by event-related functional magnetic resonance imaging. J Neurosci 2003; 23: 7839-43.

[56] Li CS, Huang C, Yan P, Bhagwagar Z, Milivojevic V, Sinha R. Neural correlates of impulse control during stop signal inhibition in cocaine-dependent men. Neuropsychopharm 2008; 33: 1798-1806.

[57] Bjork JM, Momenan R, Hommer DW. Delay discounting correlates with proportional lateral frontal cortex volumes. Biol Psychiatry 2009; 65: 710-3.

[58] Lyoo IK, Streeter CC, Ahn KH, et al. White matter hyperintensities in subjects with cocaine and opiate dependence and healthy comparison subjects. Psychiatry Res 2004; 131: 135-45.

[59] Bechara A, Dolan S, Denburg N, Hindes A, Anderson SW, Nathan PE. Decision-making deficits, linked to a dysfunctional ventromedial prefrontal cortex, revealed in alcohol and stimulant abusers. Neuropsychologia 2001; 39: 376-89.

[60] Critchley WD, Wiens S, Rotshtein P, Ohman A, Dolan RJ. Neural systems supporting interoceptive awareness. Nat Neurosci 2004; 7 : 189-95.

[61] Goldstein RZ, Craig AD, Bechara A, et al. The neurocircuitry of impaired insight in drug addiction. Trends Cog Sci 2009; 13: 37280.

[62] Naqvi NH, Rudrauf D, Damasio H, Bechara A. Damage to the insula disrupts addiction to cigarette smoking. Science 2007; 315: 531-4.

[63] Paulus MP, Feinstein JS, Leland D, Simmons AN. Superior temporal gyrus and insula provide response and outcomedependent information during assessment and action selection in a decision-making situation. NeuroImage 2005; 25: 607-15.

[64] Damasio AR. Descartes' Error. Emotion, Reason, and the Human Brain. New York: G. P. Putnam 1994.

[65] Augustine JR. The insular lobe in primates including humans. Neurol Res 1985; 7: 2-10.

[66] Goldstein RZ, Volkow ND. Drug addiction and its underlying neurobiological basis: neuroimaging evidence for the involvement of the frontal cortex. Amer J Psychiatry 2002; 159: 1642-52.

[67] Fischer B, Rehm J, Patra J, et al. Crack across Canada: Comparing crack users and crack non-users in a Canadian multi-city cohort of illicit opioid users. Addiction 2006; 101: 1760-70.

[68] Kilts CD, Gross RE, Ely TD, Drexler KPG. The neural correlates of cue-induced craving in cocaine-dependent women. Amer J Psychiatry 2004; 161: 233-41.

[69] Lejuez CW, Bornovalova MA, Curtin JJ. Risk factors in the relationship between gender and crack/cocaine. Exper Clin Psychopharm 2007; 15: 165-75.

[70] Rounsaville BJ. Treatment of cocaine dependence and depression. Biol Psychiatry 2004; 56: 803-9.

[71] Falck RS, Wang J, Carlson RG, Eddy M, Siegal HA. The prevalence and correlates of depressive symptomatology among a community sample of crack-cocaine smokers. J Psychoactive Drugs 2002; 34: 281-8.

[72] Caetano SC, Kaur S, Brambilla P, et al. Smaller cingulate volumes in unipolar depressed patients. Biol Psychiatry 2006; 59: 702-6.

[73] Hastings RS, Parsey RV, Oquendo MA, Arango V, Mann JJ. Volumetric analysis of the prefrontal cortex, amygdala, and hippocampus in major depression. Neuropsychopharm 2004; 29: 952-9.

[74] Peng J, Liu J, Nie B, et al. Cerebral and cerebellar gray matter reduction in first-episode patients with major depressive disorder: 
A voxel-based morphometry study. Europ J Radiology 2010; doi: 10.1016/j.ejrad.2010.04.006.

[75] Campbell S, MacQueen G. An update on regional brain volume differences associated with mood disorders. Curr Opin Psychiatry 2006; 19: 25-33.

[76] Koolschijn PC, van Haren NE, Lensvelt-Mulders GJ, Hulshoff Pol $\mathrm{HE}$, Kahn RS. Brain volume abnormalities in major depressive disorder: A meta-analysis of magnetic resonance imaging studies. Hum Brain Mapp 2009; 30: 3719-35.

[77] Mechtcheriakov S, Brenneis C, Egger K, Koppelstaetter F, Schocke M, Marksteiner J. A widespread distinct pattern of cerebral atrophy in patients with alcohol addiction revealed by voxel-based morphometry. J Neurol Neurosurg Psychiatry 2007; 78: 610-4.

[78] Bjork JM, Grant SJ, Hommer DW. Cross-sectional volumetric analysis of brain atrophy in alcohol dependence: effects of drinking history and comorbid substance use disorder. Amer J Psychiatry 2003; 160: 2038-45.

[79] Weller RE, Milby JB, Stoeckel L, et al. Regional brain volume reductions in cocaine-dependent men as shown by voxel-based morphometry. Soc Neurosci Abstr 2005; 31: 995.

[80] Weller RE, Stoeckel L, Milby J, et al. Regional decreases in gray matter predict cocaine cue activation in cocaine-dependent men. NeuroImage 2007; 36 (Suppl 1): S117.

(C) Weller et al.; Licensee Bentham Open.

This is an open access article licensed under the terms of the Creative Commons Attribution Non-Commercial License (http://creativecommons.org/licenses/by-nc/3.0/) which permits unrestricted, non-commercial use, distribution and reproduction in any medium, provided the work is properly cited. 